ROBERT J. GORDON

University of Chicago and the

National Bureau of Economic Research

\title{
Prices in 1970: The Horizontal Phillips Curve?
}

ECONOMISTS OF ALL PERSUASIONS, monetarists and fiscalists alike, have been surprised by the stubborn refusal of the U.S. rate of inflation to decelerate during 1970. If the beginning of the present recession is dated from the peak of industrial production in the third quarter of 1969 , four quarters of recession have now passed without any decline in the rate of advance of the nonfarm private deflator (NPD). There is no historical precedent for this, since the rate of increase of the NPD had fallen from 5.9 percent in the last four expansion quarters to -1.2 percent in the first four recession quarters in 1948-49, from 1.8 to 1.3 percent in 1953-54, from 3.6 to 1.3 percent in 1957-58, and from 1.5 to 1.1 percent in 1960-61. ${ }^{1}$ In contrast, the same pair of figures for $1969-70$ is 4.3 and 4.7 percent, so the rate of inflation has actually increased slightly. The significant rise in unemployment in 1970, accompanied by a virtually unchanged rate of inflation, contrasts with the inverse relation between inflation and unemployment - known as the Phillips curve-that is usually assumed by economists, including the administration game-plan strategists.

The first section of this report examines disaggregated evidence to determine whether the peculiar behavior of aggregate prices has been widespread or confined to specific misbehaving sectors. The second section

1. The first figure in each pair is the rate of change of the nonfarm private deflator over the four quarters ending in the final quarter of the expansion $(1948: 4,1953: 3,1957: 3$, and 1960:2), and the second figure is the rate of growth over the first four quarters of the recession. 
evaluates the recent forecasting record of the price equation for the NPD presented in these pages last spring. ${ }^{2}$

\section{The Anatomy of Inflation in 1970}

Table 1 decomposes the nonfarm private deflator into its major subcomponents (excluding government purchases from the private sector). The rate of advance of the NPD in the third quarter of 1970 was more rapid than the previous peak rate in the first quarter, but the sectoral composition was strikingly different. In 1970:1 inflation was relatively rapid in all sectors, with annual sectoral rates of change clustered in the 3.0 to 5.5 percent range. In 1970:3, however, sectoral rates were dispersed over the much wider range of 1.9 to 12.8 percent. The runaway increases in prices of structures in 1970:3 are more than enough to explain why the aggregate rate of inflation was higher in 1970:3 than in 1970:2; if these prices had grown in 1970:3 at the average rates of the preceding year, the 1970:3 rate of increase in the NPD would have been 4.5 percent rather than 5.0 percent. The behavior of sectors other than structures was less discouraging: The deflators for consumer services and producers' durable equipment maintained their average rates of increase of the preceding year, whereas a very substantial drop in the rate for consumer nondurables compared with the preceding year more than offset the small increase in the rate for consumer durables. Also, 0.1 to 0.2 percentage point of the rate of increase in the third quarter was due to the change in the composition of output that resulted from the automobile strike. There will be a further increase from this source in the fourth quarter, followed by a reversal once production reflects the make-up for the strike period.

Abstracting from the effects of the automobile strike, the near-term prospect for the NPD depends on the interpretation of the recent surge in prices of structures. There is a good chance that much of the recent bulge was temporary. The price indexes for structures do not measure actual prices but rather a weighted average of wage rates and materials costs, so the timing of wage negotiations may have accounted for the behavior of

2. "The Recent Acceleration of Inflation and Its Lessons for the Future," Brookings Papers on Economic Activity (1:1970), pp. 8-41. 
1970:3. A similar pattern occurred in the nonresidential structures deflator in 1969:3 and proved to be temporary. ${ }^{3}$ But unfortunately an improvement in the deflators for structures may have been offset to the extent that consumer goods prices rose faster after the deceleration that occurred in the second and third quarters.

Further evidence on consumer goods prices is contained in the second section of Table 1. A broadly based slowdown in the consumer price index (CPI) in 1970:3 compared with 1970:2 was followed by a speed-up in the fourth quarter. Although increases in new car prices account for some of the recent acceleration in the index for transportation, rates of advance were higher than in the third quarter in every sector listed with the sole exception of health and recreation. Sectoral rates in the fourth quarter were substantially lower than the average over the previous year only in the food and housing categories. This is not an encouraging picture, since the recent moderation in food prices is likely to be followed by an upswing in line with the usual short-term cyclical behavior of that sector, while the recent rapid rise of construction wages does not augur well for future housing prices.

The wholesale price index (WPI) has been volatile lately, due mainly to the behavior of food prices (last section of Table 1). After a decline in 1970:3, the rate of inflation for industrial commodities increased in 1970:4, due to rapid increases in all three subsectors. There is little sign in the WPI sectoral indexes of a forthcoming decline in the aggregate inflation rate.

The overall implications of Table 1 are mixed. The fourth quarter changes in the CPI and industrial WPI will lead to another increase in the NPD in the last quarter of 1970. On the other hand, the apparent failure of the NPD growth rate to decline in 1970:3 may be a statistical illusion, since construction costs increased faster in 1970:3 than in preceding quarters or than is likely in subsequent quarters because of a concentrated seasonal pattern of wage agreements.

3. The recent erratic behavior of construction wage rates confirms this hypothesis, since wage rates grew at annual rates of 7.1 percent in 1970:1, 24.9 percent in 1970:2, and 8.5 percent in 1970:3. It is unclear why there was a one-quarter lag between the rapid change of wages in 1970:2 and that of the construction price indexes in 1970:3, since the latter are simple weighted averages of wage rates and materials prices. To the extent that construction profits have declined in 1970, the rate of inflation in construction has been exaggerated, since the deflators for structures in Table 1 assume constant profit margins. 


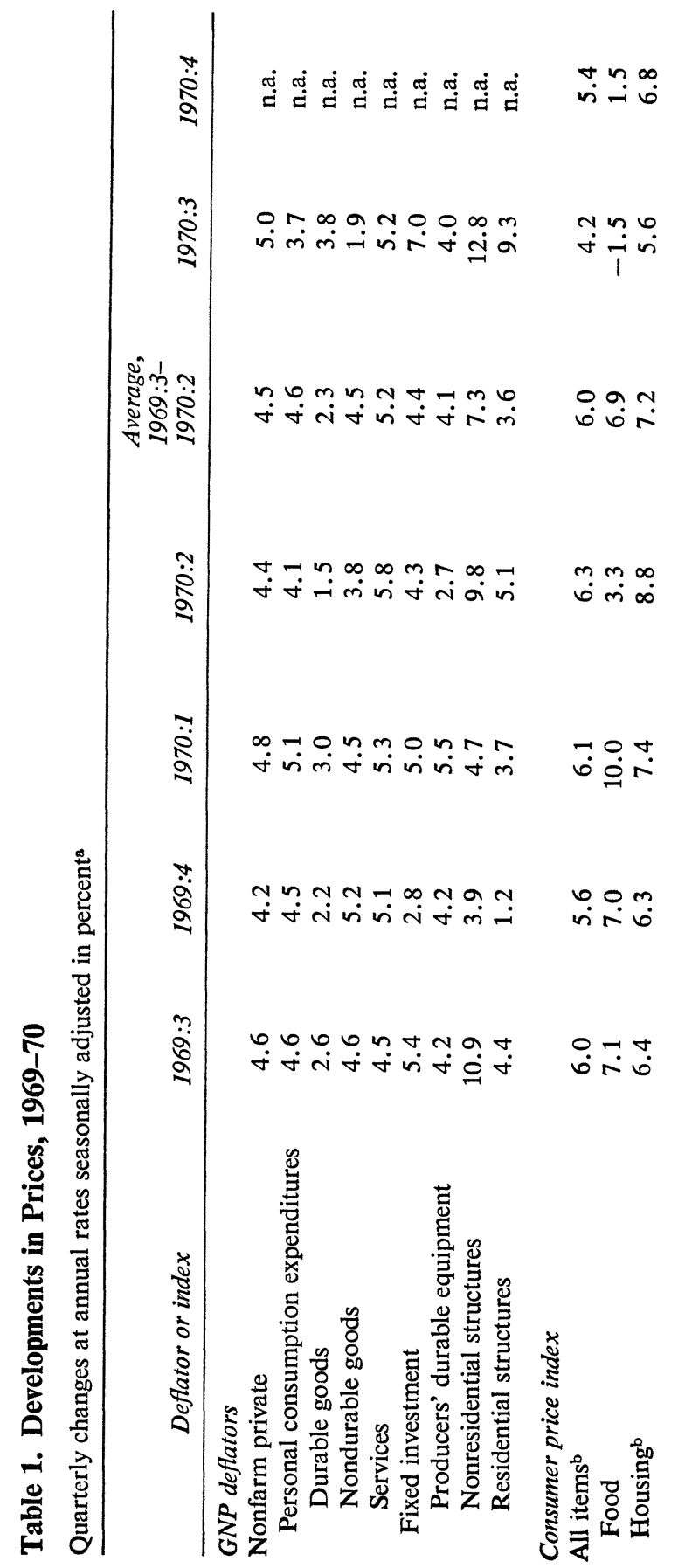




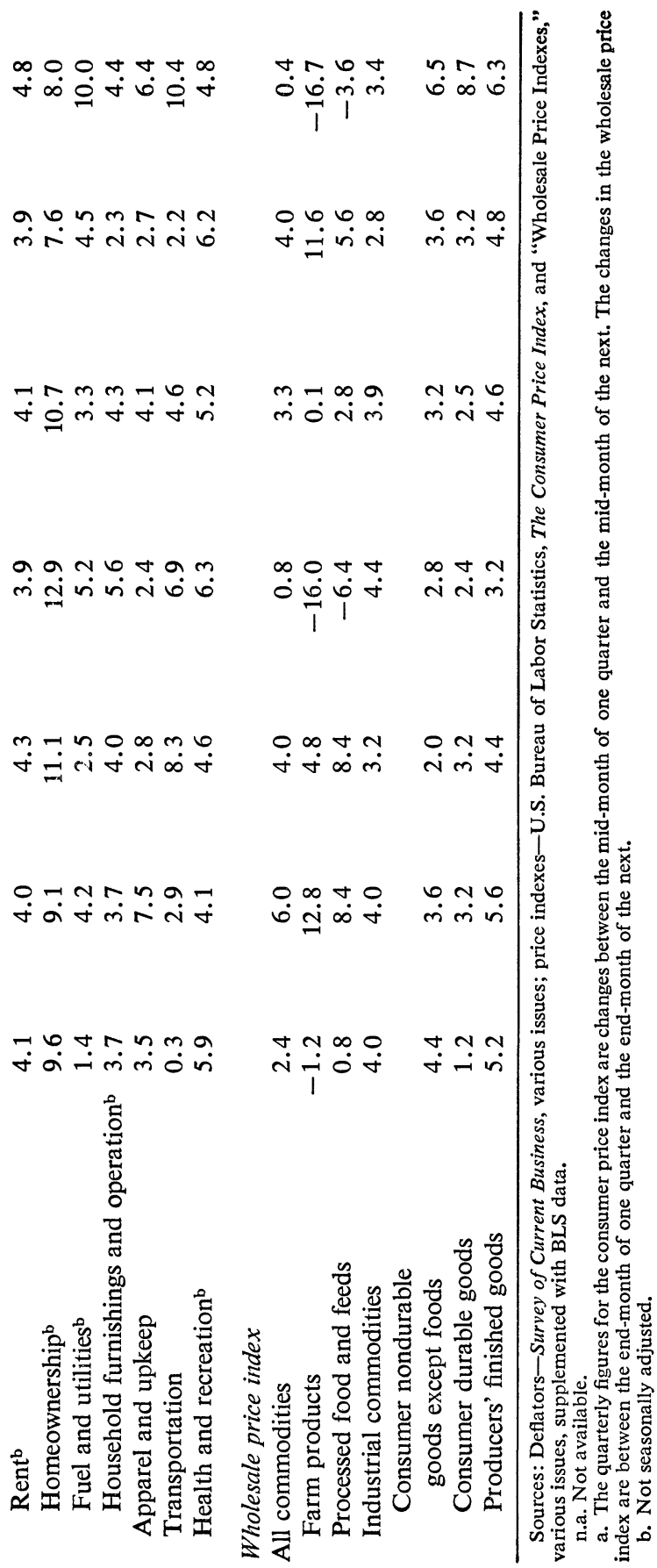




\section{The Forecasting Performance of a Price Equation}

My earlier paper (see note 2) presented forecasts of the nonfarm private deflator based on the interaction of a price equation and a wage equation. To limit the scope of this report, only the forecasts of the price equation are discussed here. Therefore, actual rather than predicted wages are inserted into the price equation, along with the values of other exogenous variables.

The behavior of wages and other exogenous variables during the 1968-70 period is illustrated in Table 2, where all values are changes over a twoquarter interval at an annual rate. The average annual rise of standard unit labor cost, which is equal to the increase of labor compensation per manhour minus a constant growth rate of "standard" productivity, increased from 4.0 percent during the four quarters of 1969 to 4.4 percent during the first three quarters of 1970 . The growth rate of the NPD increased by about the same amount between these two intervals.

In the price equation, changes in prices relative to wages are explained by the growth of unit labor cost relative to standard unit labor cost (that is, by

\section{Table 2. Changes in the Explanatory Variables in the Price Equations,}

\section{8-70}

Changes over two-quarter intervals at annual rates in percent

\begin{tabular}{rcccc}
\hline $\begin{array}{c}\text { Year } \\
\text { and } \\
\text { quarter }\end{array}$ & $\begin{array}{c}\text { Standard } \\
\text { unit labor } \\
\text { cost }\end{array}$ & $\begin{array}{c}\text { Actual } \\
\text { unit labor } \\
\text { cost }^{\mathrm{a}}\end{array}$ & $\begin{array}{c}\text { Total } \\
\text { employment } \\
\text { rate of } \\
\text { manhours }\end{array}$ & $\begin{array}{c}\text { Ratio of new } \\
\text { orders to } \\
\text { shipments }\end{array}$ \\
\hline 19681 & 5.3 & 5.2 & -0.8 & 0.6 \\
2 & 5.3 & 3.7 & 0.0 & -6.5 \\
3 & 3.6 & 3.7 & 0.8 & -3.2 \\
4 & 4.9 & 6.3 & -1.2 & 7.8 \\
19691 & 4.3 & 7.0 & 0.8 & 3.2 \\
2 & 3.0 & 6.6 & 2.3 & -4.0 \\
3 & 3.8 & 6.4 & 0.9 & -1.0 \\
4 & 5.0 & 7.1 & -0.1 & -3.6 \\
19701 & 4.7 & 8.8 & -2.4 & -7.7 \\
2 & 3.9 & 6.2 & -4.5 & -3.8 \\
3 & 4.5 & 2.7 & -4.7 & 2.5 \\
\hline
\end{tabular}

Sources: Computed from data from the U.S. Department of Commerce and the U.S. Department of Labor.

a. Here and in the text, both of the unit labor cost variables were adjusted to eliminate the influence on wages of changes in overtime and in the industrial composition of employment. 
deviations of actual from trend productivity growth), and by changes in the total employment rate of manhours and in the ratio of new orders of durables to shipments. ${ }^{4}$ Between 1968:3 and 1970:1 the growth rate of productivity was much slower than the "standard" trend rate of 2.64 percent per annum; by 1970:1 productivity had fallen 4.9 percent below the trend line. According to the price equation (that is, apart from its effects on the wage equation), this productivity shortfall was sufficient to raise the annual rate of inflation over the seven-quarter interval 0.6 percentage point above what it would have been otherwise. In 1970:2 and 1970:3 productivity increased rapidly enough to eliminate 0.8 point of the 4.9 percent productivity shortfall.

The total employment rate of manhours has declined substantially in this recession; it fell to a level of 94.0 percent in 1970:3 from a peak of 97.4 in 1969:3. This decline of 3.4 percentage points in the first four quarters of the recession compares with declines of $4.5,3.5$, and 2.3 percentage points, respectively, over the same length of time in the 1954, 1958, and 1961 recessions. The ratio of new orders of durables to shipments fell substantially in early 1970 from its 1969 level and then remained at about 0.975 in 1970:2 and 1970:3, a much higher figure than was reached in earlier postwar recessions.

From mid-1969 to the first quarter of 1970 , then, the determinants of prices relative to wages pointed in opposite directions. The productivity slump pushed up the price-wage ratio, whereas the decline in the employment rate and the orders-shipments ratio exerted a downward pressure on prices. Since the speed-up in productivity growth in 1970:2, however, all influences have worked to hold down prices relative to wages.

Given the uniform influence of the determinants of the price-wage ratio since $1970: 2$, it is not surprising to find that the price equation forecasts a substantial slowdown of the rate of inflation. In Table 3 the actual twoquarter change in the NPD is shown in the first column, and the predicted values in the columns headed equations (1), (2), and (3). Equation (1) is identical to that published previously, but it has been reestimated to allow for data revisions: ${ }^{5}$

4. Since standard unit labor cost affects prices with a lag, the price-wage ratio also depends partly on the time path of wages.

5. The equation has been reestimated with all variables expressed as one-quarter changes, whereas in the previous paper all variables were four-quarter changes. The change was made primarily to reduce the problem of serial correlation. This accounts for 
(1)

$$
\begin{aligned}
& g_{p_{t}}=0.6716 g_{\left(w / q^{\prime}\right) L}+0.2441 g_{(w / q)_{t}}+0.0194 g_{(O / S)_{t}}+0.1886 g_{m_{t}}, \\
& \text { (8.535) }
\end{aligned}
$$

in which

$$
\begin{aligned}
g_{p_{t}}= & \text { the percentage growth rate in the nonfarm private deflator } \\
g_{\left(w / q^{\prime}\right)}= & \text { the percentage growth rate in standard unit labor cost, with } \\
& \text { the } L \text { subscript indicating that the coefficient is the sum of a } \\
& \text { series of distributed lag coefficients } \\
g_{(w / q)_{t}}= & \text { the percentage growth rate in actual unit labor cost } \\
g_{(o / S)_{t}}= & \text { the percentage growth rate in the ratio of new orders of dura- } \\
& \text { bles to shipments } \\
g_{m_{t}}= & \text { the percentage growth rate in the total employment rate of } \\
& \text { manhours in the entire economy. }
\end{aligned}
$$

The forecast and errors for equation (1) are shown in Table 3. The equation does moderately well in 1968 and 1969, with a mean absolute error of 0.40 percentage point, and forecasts accurately for 1970:1. But extremely large errors are made in 1970:2 and 1970:3 as a price deceleration is forecast that does not occur.

Two minor alterations in the equation lead to a substantial reduction of the 1970 prediction error. First, the equation performs better when the sample period is shortened to eliminate the Korean war period:

$$
\begin{aligned}
& g_{p_{t}}=0.8267 g_{\left(w / q^{\prime}\right)_{L}}+0.1694 g_{(w / q)_{t}}+0.0051 g_{(O / S)_{t}}+0.1522 g_{m_{t}} \text {. } \\
& \text { (13.205) } \\
& \text { (5.005) } \\
& \text { (0.962) } \\
& \bar{R}^{2}=0.750 \text {, Durbin-Watson }=2.26 \text {, standard error }=0.0019 \text {, } \\
& \text { sample period }=1954: 2-1969: 4 \text {. }
\end{aligned}
$$

The predictions and errors with equation (2) are shown in Table 3 . A substantial price deceleration is predicted to occur by equation (2), but the magnitude of the predicted decline in the rate of inflation between 1970:1 and 1970:3 is less than it is with equation (1). This occurs because the elimination of the Korean war period raises the coefficient on standard unit

the decline in $R^{2}$. The only coefficient substantially altered by the change is that on the orders-shipments ratio, which is reduced in equation (1) and becomes statistically insignificant in equations (2) and (3). 
Table 3. Predictions of the Behavior of the Nonfarm Private Deflator by Alternative Equations, 1968-70

Two-quarter changes at annual rates in percent

\begin{tabular}{|c|c|c|c|c|c|c|c|}
\hline \multirow[b]{2}{*}{$\begin{array}{l}\text { Year } \\
\text { and } \\
\text { quarter }\end{array}$} & \multirow{2}{*}{$\begin{array}{c}\text { Actual } \\
\text { nonfarm } \\
\text { private } \\
\text { deflator }\end{array}$} & \multicolumn{3}{|c|}{$\begin{array}{l}\text { Predicted nonfarm } \\
\text { private deflator }\end{array}$} & \multicolumn{3}{|c|}{ Error (actual minus predicted) } \\
\hline & & $\begin{array}{c}\text { Equa- } \\
\text { tion } \\
(1)\end{array}$ & $\begin{array}{c}\text { Equa- } \\
\text { tion } \\
(2)\end{array}$ & $\begin{array}{c}\text { Equa- } \\
\text { tion } \\
(3)\end{array}$ & $\begin{array}{l}\text { Equa- } \\
\text { tion } \\
\text { (1) }\end{array}$ & $\begin{array}{c}\text { Equa- } \\
\text { tion } \\
(2)\end{array}$ & $\begin{array}{c}\text { Equa- } \\
\text { tion } \\
(3)\end{array}$ \\
\hline 19681 & 3.4 & 3.8 & 3.6 & 3.5 & -0.4 & -0.2 & -0.1 \\
\hline 2 & 3.2 & 3.8 & 3.8 & 3.8 & -0.6 & -0.6 & -0.6 \\
\hline 3 & 3.6 & 3.8 & 3.7 & 3.7 & -0.2 & -0.1 & -0.1 \\
\hline 4 & 3.9 & 4.5 & 4.1 & 3.8 & -0.6 & -0.2 & 0.1 \\
\hline 19691 & 4.3 & 4.9 & 4.5 & 4.4 & -0.6 & -0.2 & -0.1 \\
\hline 2 & 4.1 & 4.6 & 4.3 & 4.4 & -0.5 & -0.2 & -0.3 \\
\hline 3 & 4.1 & 4.3 & 4.1 & 4.2 & -0.2 & 0.0 & -0.1 \\
\hline 4 & 4.4 & 4.5 & 4.3 & 4.4 & -0.1 & 0.1 & 0.0 \\
\hline 19701 & 4.5 & 4.5 & 4.4 & 4.2 & 0.0 & 0.1 & 0.3 \\
\hline 2 & 4.6 & 3.4 & 3.6 & 3.7 & 1.2 & 1.0 & 0.9 \\
\hline 3 & 4.5 & 2.7 & 3.1 & 3.3 & 1.8 & 1.4 & 1.2 \\
\hline \multicolumn{8}{|c|}{ Mean absolute error } \\
\hline \multicolumn{8}{|c|}{$1968: 1-$} \\
\hline 1969:4 & $\cdots$ & $\cdots$ & $\cdots$ & $\cdots$ & 0.40 & 0.20 & 0.18 \\
\hline $\begin{array}{l}1970: 1- \\
1970: 3\end{array}$ & $\ldots$ & $\ldots$ & $\ldots$ & $\ldots$ & 1.00 & 0.83 & 0.80 \\
\hline
\end{tabular}

Sources: Actual data, see Table 1; predictions, author's estimates.

labor cost, which tends to raise the 1970 forecast; the coefficients on all the other variables are reduced, and this also raises the 1970 forecast because these variables all act in 1970:2 and 1970:3 to depress the NPD.

Both equations (1) and (2) allow distributed lags only on the standard unit labor cost variable and thus force the influence of productivity change to affect prices immediately. Although numerous other specifications are possible, the results from equation (3) illustrate just one alternative, which differs from the previous equations in allowing separate distributed lags on productivity and wages. Thus variations in the growth of productivity influence prices gradually rather than suddenly: ${ }^{6}$

6. In equation (3) the sum of the distributed lag coefficients rate of growth of actual/ trend productivity ratio is not significantly different from zero, because the influence of an initial four quarters with significantly positive coefficients is partially canceled out by a series of small negative coefficients in later quarters. 
(3)

$$
\begin{aligned}
& g_{p_{t}}=0.9984 g_{\left(w / q^{\prime}\right)_{L}}+0.1464 g_{\left(q / q^{\prime}\right)_{L}^{\prime}}+0.0059 g_{(O / S)_{t}}+0.1781 g_{m_{t}}, \\
& \text { (18.734) (0.517) (1.061) } \\
& \bar{R}^{2}=0.726 \text {, Durbin-Watson }=2.19 \text {, standard error }=0.0020 \text {, } \\
& \text { sample period }=1954: 2-1969: 4 \text {. }
\end{aligned}
$$

where

$g_{\left(q / q^{\prime}\right) L}=$ the rate of growth of the ratio of actual to trend productivity.

Since the productivity acceleration of $1970: 2$ and $1970: 3$ reduces the predicted price-wage ratio only gradually in equation (3), the price deceleration forecast (see Table 3 ) is more moderate than that in equations (1) and (2). But the alteration of the lag pattern does not change the basic conclusion of the earlier paper: An acceleration of productivity growth above its trend rate will reduce the growth rate of prices relative to wages and hence tend to dampen the inflationary process, just as the productivity shortfall of 1968:3-1970:1 was a major contributor to the severity of the 1969-70 inflation.

Thus if the rate of change of wages is no faster in 1971 than in 1970, and if the productivity rebound continues at anything like its present pace, a slackening in inflation in 1971 is very likely if statistical relationships fitted to earlier periods of the postwar economy have any validity at all. But all statements that relate 1971 to earlier periods by statistical methods must be made cautiously, since the response of prices to the altered economic environment of 1970 has been distinctly more sluggish than previous history led us to predict. 